\title{
Design of Virtual Simulation Experiment Project for Steam Turbine DEH System Oriented to Engineering Education
}

\author{
Yuliang Dong* \\ Department of Energy Power \& Mechanical Engineering \\ North China of Electric Power University \\ Beijing, China \\ Chengbing He \\ Department of Energy Power \& Mechanical Engineering \\ North China of Electric Power University \\ Beijing, China
}

\author{
Zhiping Yang \\ Department of Energy Power \& Mechanical Engineering \\ North China of Electric Power University \\ Beijing, China
}

\author{
Aijun $\mathrm{Wu}$ \\ Beijing Xiangxinli Technology Co., LTD \\ Beijing, China
}

\begin{abstract}
Experimental teaching is an important part of engineering education. Aiming at the problem that the current DEH simulation experiment system cannot meet the experimental requirements in terms of experimental capacity, innovation, interaction, openness and sharing, a virtual simulation experiment project of DEH system is designed. The design of the project adopts the principle of "combining virtual with real", and the designed virtue simulation experimental network platform can meet the experimental requirements in experimental function and content. As a result, the development of the project is of great significance to promote the reform of teaching mode and method, and to promote students' independent learning, research learning and innovative learning.
\end{abstract}

Keywords-engineering education; steam turbine; DEH; virtual simulation experiment

\section{INTRODUCTION}

Experimental teaching is a very important part of engineering education. Through experimental teaching, the theoretical knowledge of the course can be verified, the cognitive effect of students can be deepened, the advanced analytical methods can be mastered, the theoretical knowledge can be deepened, and the engineering practice ability of students can be improved[1].

"Steam turbine principle" is one of the core courses of energy and power engineering specialty in North China Electric Power University, which lacks the teaching and experimental system of digital electro-hydraulic regulating system (DEH), which is not conducive to students' good understanding and application of the principle and method of steam turbine control[2]. At the same time, as a course of professional master's degree student, "Steam turbine performance test and operation optimization" also needs DEH experimental system to improve students' engineering practice ability. At present, the construction of steam turbine DEH system simulation experimental platform has been basically completed. However, after the completion of the experimental platform, the experimental capacity, innovation, interaction, openness and sharing still cannot meet the requirements of experimental teaching.

Virtual Reality (VR) is the latest technology in the computer field, which combines computer graphics technology, multimedia technology, sensor technology, human-computer interaction technology, network technology, stereo display technology and simulation technology. It is also an integrated application technology of mechanics, mathematics, optics, mechanism kinematics and other theories. By generating virtual environments with visual, auditory and tactile functions close to the real world, users can perform various operations in the virtual environment[3]. Virtual simulation experiment teaching based on VR technology is an important part of higher education informationization in China, and it is also one of the important development directions of higher education experiment teaching in China[4-6].

The virtual simulation experiment of steam turbine DEH is a necessary supplement to the simulation experiment platform. On the one hand, it improves the experimental teaching conditions through the combination of virtual and real, helps students comprehensively understand and master the advanced theory and technology of steam turbine control, completes the experimental teaching functions that are not available or difficult to complete in real experiments, and draws closer to the experimental teaching and engineering. On the other hand, it can be used as a breakthrough in the reform of school teaching mode and teaching method to promote students' autonomous learning, research learning, innovative learning and paperless learning.

\section{SimUlation EXPERIMENTAL DEVICE}

The DEH simulation experiment system is composed of the test station and the simulation system of steam turbine

This research has been funded by Postgraduate "Double Firstclass" Top-notch Innovative Talents Training Project 
generator set. The experimental system topology is shown in

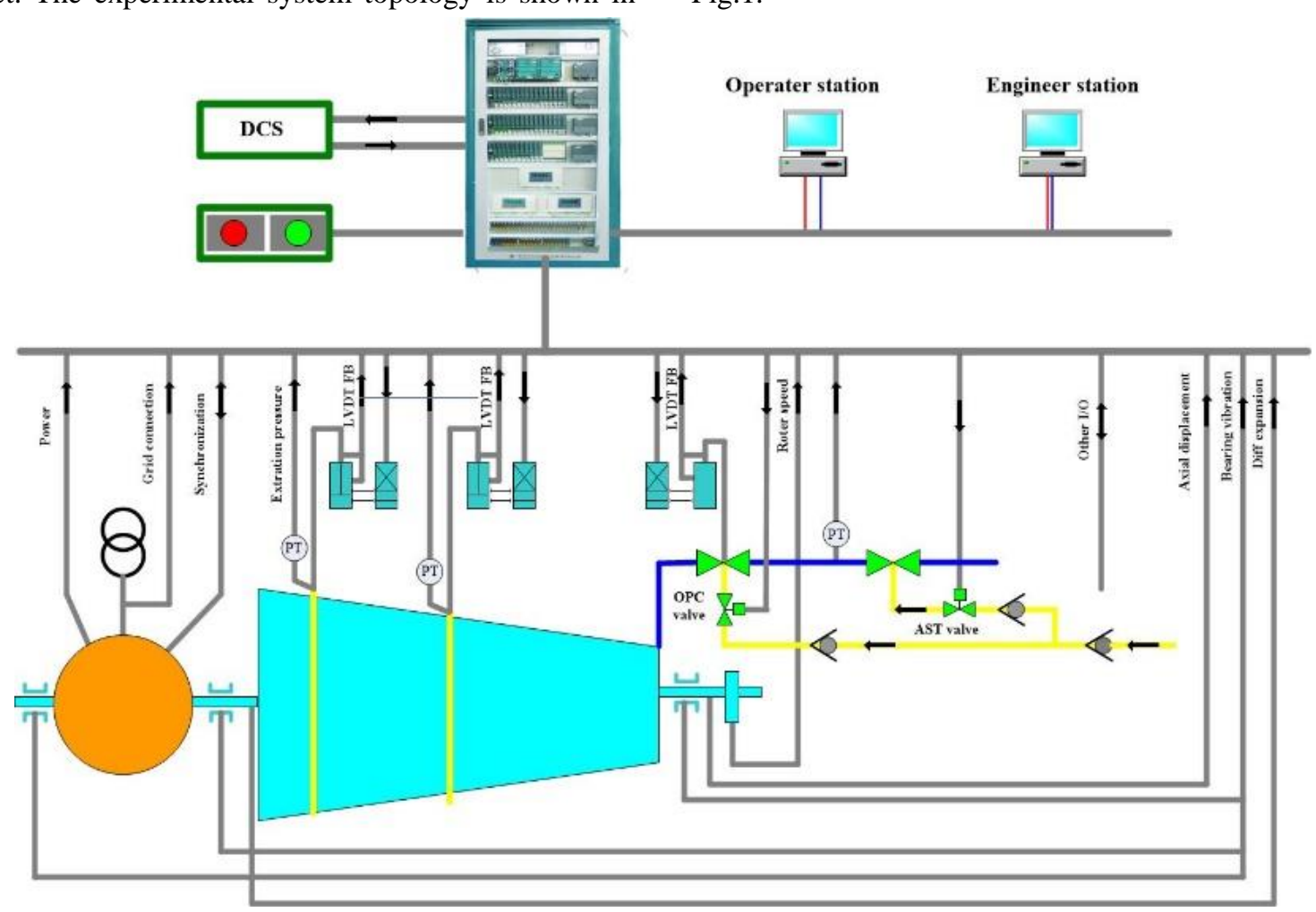

Fig.1. Structure Diagram of DEH Simulated Experiment System

DEH test station is composed of electronic control system and hydraulic servo system. Human-computer interaction is realized through operator station and engineer station. The electronic control system includes three subsystems, DEH, ETS and TSI, which are integrated in a cabinet. As shown in Fig. 2, the experimental device of hydraulic servo system mainly includes two main valves, six regulating valves, each with an independent servo motor; six MOOG761 servo valves, four AST solenoid valves, two OPC solenoid valves and two ETS solenoid valves; one main pump motor, one circulating pump motor, and temperature sensors; also equipped with air cooler, heater, pressure switch, fuel tank, oil pump and so on.

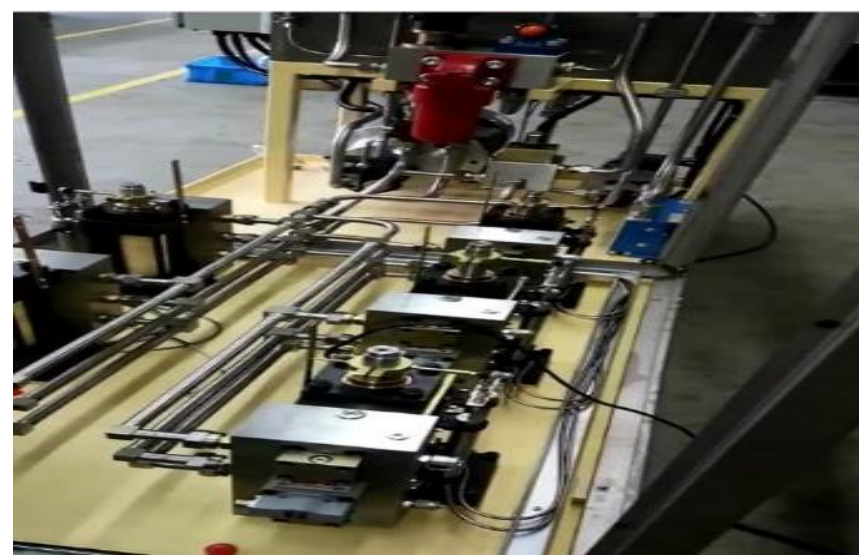

Fig.2. Experiment Device of DEH Hydraulic Servo System
The simulation system realizes the analog control of steam turbine equipment through pure digital simulation, and can set up various working conditions and fault conditions. The simulation system is equipped with two computers, and the simulation software and model are installed.

The simulation experiment system can be used to realize normal and abnormal operation of steam turbine generator units, including cold, hot, extremely hot start-up and shutdown, as well as load-up/load-down operation and load-control mode. It can also be used to do on-line test of DEH system, including over-speed protection test, valve management test (valve test, valve loosening test, tightness test, single valve multi-valve switching test), ETS trip test (including low vacuum, low lubricating oil pressure, low EH oil pressure, AST solenoid valve, etc.), ETS channel test. In addition, fault simulation, demonstration and treatment can also be conducted using the simulation experiment system.

The use of this simulation experiment system can help students understand the control principle and method of steam turbine DEH system and improve their engineering practice ability. However, there are some problems as follows: (1) Only one system can't meet the requirements of active students' hands-on experiment; (2) The working process of hydraulic servo system is complex and its components are precise. It is difficult for students to study the internal structure and working process of the components in depth; (3) the experimental process is fixed, which can't meet the requirements of innovative experiments; (4) there is no open and shared experimental conditions. Based on the above problems, the 
research of DEH virtual simulation experiment system is carried out.

\section{DESIGN OF DEH VIRTUAL SIMULATION EXPERIMENT PROJECT}

\section{A. The Workflow of Designing DEH Virtual Simulation Experiment Project}

Firstly, the virtual simulation experiment teaching mode of steam turbine DEH system is studied, then the experiment content of the main experiment teaching module is designed, and finally the software design of the whole virtual simulation experiment project is completed. As shown in Fig.3.

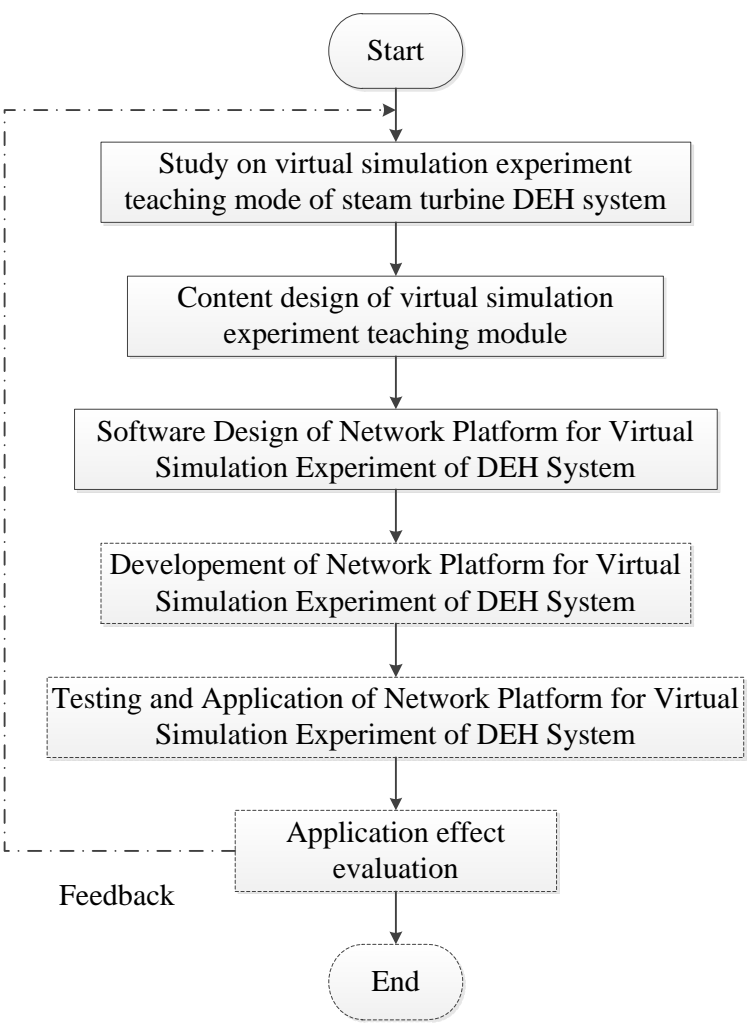

Fig.3. Construction Ideas of Virtual Simulation Network Experiment Platform for DEH System

The research of virtual simulation experiment teaching mode of DEH system mainly includes the research of virtual simulation experiment teaching idea, experiment teaching method, experiment teaching process (including teachers, students, and systems), network sharing mechanism of experiment teaching resources, etc. The modular design of virtual simulation experiment teaching content of DEH system mainly carries out virtual simulation. The software design of DEH system virtual simulation experiment network platform mainly includes software system architecture, function design, experimental teaching business process design, experimental teaching resources network sharing process design, interface design with existing DEH simulation experiment system. The development of an experimental network platform is based on the design of the platform, using the mode of school-enterprise cooperation to realize the development of a virtual simulation experimental teaching platform. Finally, the whole system is testified and perfected through the platform testing, practical application and effect evaluation.

\section{B. Experimental Teaching Model of "Combination of Virtuality and Reality"}

Virtual experiment and physical experiment have a good complementarity. In a virtual experiment environment, students will form a relatively intuitive impression by using their own observation and analysis of the model. Then they will use the operation of various equipment functions to understand, strengthen the understanding of experimental principles and rules, and form a preliminary recognition. Knowledge skills and operation skills, and positive transfer effect in physical experiments can effectively promote the development and completion of physical experiments, and enable students to constantly improve their own practical skills in practice.

\section{Content Design of DEH System Virtual Simulation Network Platform}

- Construction experiment of DEH test station. By using three-dimensional modeling of DEH system components, students can use the established graphics library and help files to build the DEH control system test station, which is helpful for students to understand the structure and working principle of DEH control system.

- Disassembly experiment of important components. The structure of DEH hydraulic servo system is precise and its working principle is complex. Through threedimensional modeling, disassembly experiments of the main valve, regulating valve, electro-hydraulic converter, oil engine, quick unloading valve, crisis blocker, AST/OPC solenoid valve and other important components can be carried out, which is helpful for students to understand the structure and working principle of these key components.

- Static and Dynamic Characteristic Experiments of DEH Regulating System. The static and dynamic characteristics of DEH regulating system directly affect the control performance of DEH system. The students observe the static and dynamic characteristics of the regulating system by changing the parameters of the regulating system and the regulating object (such as vertiginous rate, stagnant rate, time constant of the engine, time constant of the rotor flying, etc.), and understand the influence of the parameters on the performance of the regulating system.

- Operation Control Experiment of DEH System. In this module, the students can carry out routine control function experiments of DEH system, such as start/stop control experiment, speed control experiment, power control experiment, and main steam pressure control experiment and so on

- Performance test of DEH system. In this module, the students can carry out routine performance tests of DEH 
system, such as overspeed protection test, ETS trip test, valve management test, etc.

- Failure Mode and Accident Treatment. In this module, the students can simulate common faults of $\mathrm{DEH}$ system, and use their own knowledge to analyze and deal with them.

\section{Functional Design of DEH Virtual Simulation Experiment Platform}

1) System structure

The system structure of the virtual simulation experiment platform for DEH system is shown in Fig.4.

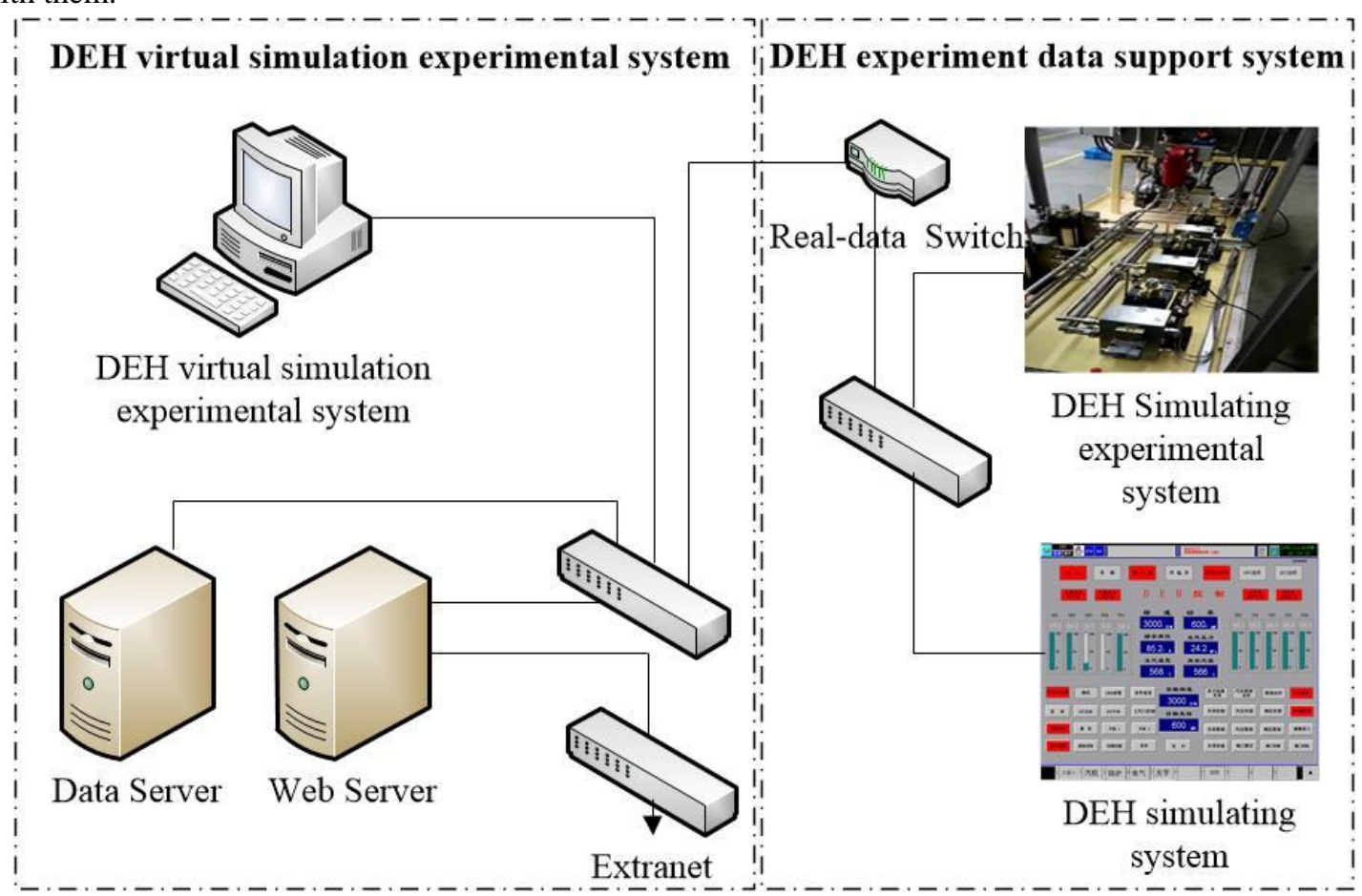

Fig.4. System structure of Virtual Simulation Experiment Platform for DEH System

The virtual simulation experiment system of DEH consists of two parts, which are virtual simulation experiment teaching system and experimental data/case support system. The former mainly includes data servers, web servers and application software. Students can do experiments in virtual simulation experiment center, on mobile phones or computers through campus network. The latter includes DEH mode experiment system and simulation system, which together provide data and case support for virtual simulation experiment teaching system.

2) The business process design of experimental teaching

In the course of the experiment, the students' operation steps are divided into three parts, totaling 16 steps. The operation steps are as follows:

- Step $1 \mathrm{DEH}$ virtual simulation experiment system login. After login, there are menus such as experiment introduction, experiment requirement, result determination, teaching team, and online discussion and so on in the main web page of the experimental system.

- Step 2 Browse the basic situation and requirements of the learning experiment.

- Step 3: Familiarize yourself with the experimental environment and basic operation according to the experimental procedure and operation in the experimental operation interface.

- Step 4 DEH virtual simulation system construction training

- Step 5 Disassembly training for key components of DEH system

- Step 6 Control parameter setting experiment of DEH system.

- Step 7 Static Characteristic Experiment of DEH System

- Step 8 Dynamic Characteristic Experiment of DEH System

- $\quad$ Step 9 Unit Start/Stop Test

- Step 10 Turbine Speed Control, Load Control and Steam Pressure Control Experiments

- $\quad$ Step 11 Overspeed Protection Test

- $\quad$ Step 12 ETS Trip Test

- $\quad$ Step 13 Valve Management Test

- Step 14 Simulation and Treatment of Swing Fault in Regulating System 
- Step 15 Fault simulation and treatment of LVDT sensor

- $\quad$ Step 16 Gate jamming fault simulation and treatment.

\section{E. Project Development, Testing and Application}

After completing the software design of DEH system virtual simulation experiment network platform, we cooperate with professional virtual simulation software company to develop three-dimensional animation modeling of DEH system, develop interface software with existing DEH simulation experiment system, and finally, develop application software of DEH system virtual simulation experiment network platform. Through project testing, practical application and effect evaluation, the whole project is revised and perfected.

\section{CONCLUSION}

In the teaching of the steam turbine DEH control system, because of the complexity of DEH system, it is difficult for students to deeply understand the internal structure and working principle of the system equipment through physical experiments. Using virtual reality technology, the threedimensional virtual simulation model of system and components is established. According to the principle of a combination of virtual and real, a highly simulated virtual experiment platform of DEH system and a reliable, safe and economical teaching experiment project are designed based on the hardware of DEH simulation experiment system. Through this experiment, we can carry out the exploration of engineering-oriented open experimental teaching with students as the main body. Students can understand the internal structure, system composition and working principle of each component of DEH control system, and can carry out comparative and innovative experiments on the virtual platform. This project-oriented open teaching mode with students as the main body can fully mobilize students' enthusiasm and initiative in learning and improve students' practical ability.

\section{ACKNOWLEDGMENT}

This research has been funded by the Postgraduate "Double First-class" Top-notch Innovative Talents Training Project 2019, the support of which is gratefully acknowledged and appreciated.

\section{REFERENCES}

[1] M. Hernandez-de-Menendez, R. Morales-Menendez. "Technological innovations and practiced in engineering education: a review," IJIDeM, vol 13, pp. 713-728, 2019

[2] S. Huang, Steam turbine, Beijing, 2008, pp. 234-245. (In Chinese)

[3] G. Makransky, T. S. Terkildsen, R. E. Mayer. "Adding immersive virtual reality to a science lab simulation causes more presence but less learning,".Learning and Instruction, vol 60, pp. 225-236, 2019.

[4] J. Wu, G. Ren, D. Huang, J. Liu, "Research and implementation of practical teaching reform based on virtual simulation technology," Research and exploration in laboratory, vol 37, pp. 240-244, 2018. (In Chinese)

[5] C. Tian, M. Qi, "Design of virtual simulation experiment project for steam turbine generation," Experimental technology and management, vol 36, pp. 121-124, Jan, 2019. (In Chinese)

[6] D. Ma, X. Zhang, Y. Hu, Y. Liu. "Construction of virtual simulation experimental teaching center for construction machinery," Research and exploration in laboratory, vol 38, pp. 143-147, Apr. 2019. (In Chinese) 